Trauma Surgery \& Acute Care Open

\title{
Neurological outcomes after traumatic cardiopulmonary arrest: a systematic review
}

\author{
Daniel Shi, ${ }^{1}$ Christie McLaren, ${ }^{1}$ Chris Evans ${ }^{2}$
}

\begin{abstract}
- Additional supplemental material is published online only. To view, please visit the journal online (http://dx.doi. org/10.1136/tsaco-2021000817).
\end{abstract}

'School of Medicine, Queen's University, Kingston, Ontario, Canada

2Emergency Medicine, Queen's University, Kingston, Ontario, Canada

Correspondence to Daniel Shi; dshi@qmed.ca

This study was presented as an oral presentation at the Annual Meeting of the Trauma Association of Canada in a virtual format on April 12, 2021

Received 3 August 2021 Accepted 10 October 2021

(C) Author(s) (or their employer(s)) 2021. Re-use permitted under CC BY-NC. No commercial re-use. See rights and permissions. Published by BMJ.

To cite: Shi D, McLaren C, Evans C. Trauma Surg Acute Care Open 2021:6:e000817.

\section{ABSTRACT}

Background Despite appropriate care, most patients do not survive traumatic cardiac arrest, and many survivors suffer from permanent neurological disability. The prevalence of non-dismal neurological outcomes remains unclear.

Objectives The aim of the current review is to summarize and assess the quality of reporting of the neurological outcomes in traumatic cardiac arrest survivors.

Data sources A systematic review of Embase, Medline, PubMed, Cumulative Index to Nursing and Allied Health Literature (CINAHL), and ProQuest databases was performed from inception of the database to July 2020. Study eligibility criteria Observational cohort studies that reported neurological outcomes of patients surviving traumatic cardiac arrest were included.

Participants and interventions Patients who were resuscitated following traumatic cardiac arrest.

Study appraisal and synthesis methods The quality of the included studies was assessed using ROBINS-I (Risk of Bias in Non-Randomized Studies - of Interventions) for observational studies.

Results From 4295 retrieved studies, 40 were included ( $n=23644$ patients). The survival rate was $9.2 \%$ $(n=2168$ patients). Neurological status was primarily assessed at discharge. Overall, $45.8 \%$ of the survivors had good or moderate neurological recovery, $29.0 \%$ had severe neurological disability or suffered a vegetative state, and $25.2 \%$ had missing neurological outcomes. Seventeen studies qualitatively described neurological outcomes based on patient disposition and 23 studies used standardized outcome scales. 28 studies had a serious risk of bias and 12 had moderate risk of bias. Limitations The existing literature is characterized by inadequate outcome reporting and a high risk of bias, which limit our ability to prognosticate in this patient population.

Conclusions or implications of key findings Good and moderate neurological recoveries are frequently reported in patients who survive traumatic cardiac arrest. Prospective studies focused on quality of survivorship in traumatic arrest are urgently needed.

Level of evidence Systematic review, level IV. PROSPERO registration number CRD42020198482.

\section{BACKGROUND}

Traumatic cardiac arrest (TCA) occurs due to severe injury, most commonly from traumatic brain injury and hemorrhage. ${ }^{1}$ Despite appropriate care, TCA has been associated with extremely low survival rates, with $2 \%$ of patients surviving to hospital discharge. $^{2}$ Some authors have even concluded that resuscitation of patients with TCA is futile and costly. ${ }^{3}$ However, recent data from prospectively registered trauma systems in England, Spain, and North America have suggested that outcomes from TCA may be better than previously expected, with overall survival rates between $5.7 \%$ and $7.5 \% .^{4-6}$ Advances in damage control resuscitation and our understanding of its pathophysiology have led to improvements in the contemporary management of TCA, which is at least partially responsible for the observed increase in overall survival. ${ }^{7}$

The prognostication of patients with TCA is an important consideration for patients, families, and health providers that initiate resuscitative efforts, as after survival the main treatment goal is a favorable neurological outcome. ${ }^{3} 8$ Poor outcomes after cardiac arrest of any etiology have been attributed to hypoxic-ischemic brain injury. ${ }^{9}$ The extent of this brain injury is an important predictor of unfavorable neurological outcomes, which are defined by death from neurological cause, persistent vegetative state, or severe neurological disability. ${ }^{9}$ Most studies examining cardiac arrest outcomes use the Cerebral Performance Categories (CPCs) or the Glasgow Outcome Scale (GOS) to report neurological status. ${ }^{9}$ Other scales that have demonstrated value in assessing the neurological outcome of survivors include the modified Rankin Scale (mRS), the Extended Glasgow Coma Scale (GOSE), and the Functional Independence Measure (FIM). ${ }^{10-12}$ Despite the existence of several validated measures, in many neuroprognostication studies, neurological outcomes are generally dichotomized as "good" or "poor", with no consensus on how a poor outcome is defined. ${ }^{9}$ The neurological outcome of these patients remains unclear in the current literature. Among TCA survivors, residual neurological deficits have generally been found to be severe and disabling in small observational studies. ${ }^{13}{ }^{14}$ However, a systematic review in 2012 found that more than half of TCA survivors either make a full neurological recovery or have moderate deficits. ${ }^{15}$

Although previous literature has focused on summarizing the proportion of survivors and identifying resuscitation techniques to reduce mortality in traumatic arrest, minimal evidence exists that assesses the quality of neurological outcome data. Hence, we performed a systematic review to summarize the neurological outcomes of patients who survive TCA. Particular attention was placed on the variation of reporting and definitions of these outcomes between studies. 


\section{METHODS}

This review was conducted in accordance with the Cochrane Handbook for Systematic Reviews of Interventions and followed the Preferred Reporting Items for Systematic Reviews and MetaAnalyses statement. ${ }^{16}$ The protocol for this study was registered with the International Prospective Register of Systematic Reviews.

\section{Inclusion criteria}

Eligible studies included observational cohort studies that enrolled patients who experienced cardiopulmonary arrest following trauma and reported neurological outcomes. Studies examining pediatric patients were included. We excluded case reports, case series studies, reviews, and animal studies. Studies published in the English language were included. There were no restrictions on the length of follow-up, geographical location, or publication date.

\section{Study selection and data abstraction}

A systematic search of Embase, Medline, PubMed, Cumulative Index to Nursing and Allied Health Literature (CINAHL), and ProQuest was conducted from the inception of the database to July 2020. A librarian with methodological and content expertise was consulted to create the search strategies (online supplemental table 1). Medical subject headings and Emtree headings were used in their respective databases.

Two reviewers (DS and CM) independently screened the title and abstract of all included studies. Duplicate studies were removed using Covidence. ${ }^{17}$ Studies that met the inclusion criteria were reviewed in full text by the same two reviewers independently (figure 1). Disagreements were resolved by consensus or by the decision of a third independent reviewer (CE). Interobserver agreements for the title/abstract and full text stages were calculated using Cohen's $\kappa$ statistics. ${ }^{18}$

Data were abstracted by two independent reviewers using a piloted data abstraction form (Microsoft Excel). The primary outcome was the neurological status of TCA survivors which was abstracted from each study. Additionally, the methods used to assess neurological outcome, the mechanism of trauma, and the time point when neurological status was measured were abstracted.

\section{Data analysis}

Patients from the included studies were placed into one of four categories to describe their neurological outcome: good, moderate, poor, or vegetative. A "good" neurological outcome was defined as a full neurological recovery or having minor deficits. A "moderate" outcome was defined as having neurological disability that partially affects daily activities but having full independence. A "poor" outcome was defined as requiring any level of dependency or personal assistance in daily living. A "vegetative" outcome was defined by unresponsiveness to external stimuli and a decreased level of awareness.

The proportion of patients with "favorable" neurological outcomes (ie, patients with good or moderate outcome) versus
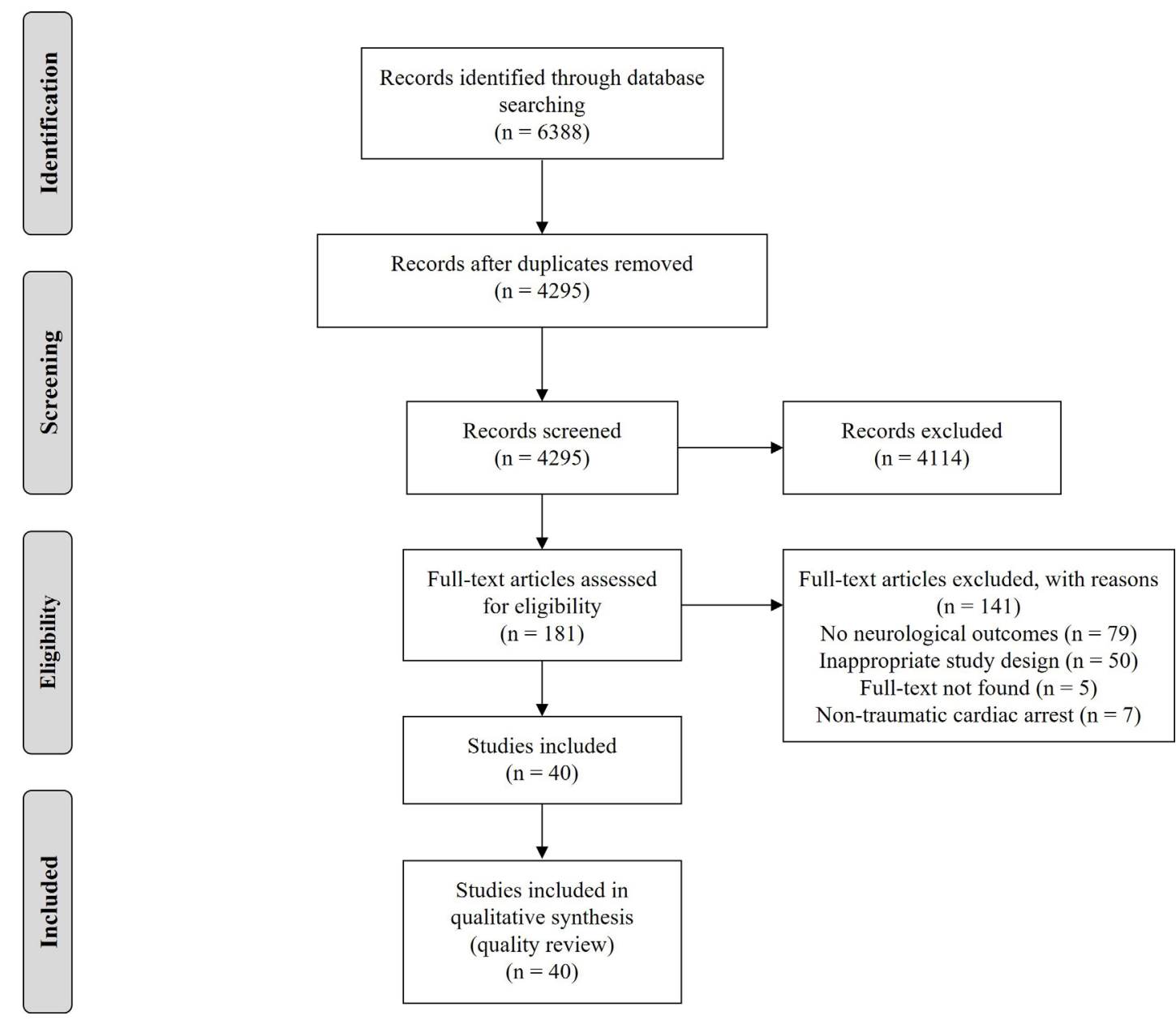

Figure 1 PRISMA diagram. PRISMA, Preferred Reporting Items for Systematic Reviews and Meta-Analyses. 
patients with "unfavorable" neurological outcomes (ie, patients with poor or vegetative outcome) was also calculated.

\section{Quality assessment}

The quality of included studies was assessed using ROBINS-I (Risk of Bias in Non-Randomized Studies - of Interventions) tool for observational studies. The overall risk of bias was rated as critical, serious, moderate, or low. Quality assessment was completed by two independent reviewers (DS and CM), with all conflicts resolved by consensus or discussion with a third reviewer (CE).
RESULTS

Study characteristics

After the removal of duplicates, the literature search generated 4295 citations for title and abstract review. One hundred and eighty-one qualified for full-text screening, of which 40 were included in our analysis (figure 1). The title and abstract screening showed almost perfect agreement $(\kappa=0.83)$, and similar agreement was found for the full-text screening $(\kappa=0.87)$. Of the included studies, 35 were retrospective cohort studies and 5 were prospective cohort studies (table 1). The included studies were published between 1983 and 2019, with 12 studies published in the past 5 years.

Table 1 Characteristics of included studies

\begin{tabular}{|c|c|c|c|c|c|c|c|c|}
\hline Study identification & Design & Age group & Sample size & Survivors (n) & Mortality (\%) & Blunt trauma & $\begin{array}{l}\text { Penetrating } \\
\text { trauma }\end{array}$ & $\begin{array}{l}\text { Other/unknown } \\
\text { trauma type }\end{array}$ \\
\hline Alanezi45 2004 & Prospective cohort & Mixed & 50 & 2 & 96.0 & 4 & 46 & 0 \\
\hline Barnard 2017 & Retrospective cohort & Mixed & 705 & 53 & 92.5 & 601 & 104 & 0 \\
\hline Beck $^{46} 2016$ & Retrospective cohort & Mixed & 1354 & 9 & 99.3 & 869 & 226 & 259 \\
\hline Calkins ${ }^{34} 2002$ & Retrospective cohort & Pediatric & 25 & 2 & 92.0 & 25 & 0 & 0 \\
\hline Capizzani35 2010 & Retrospective cohort & Pediatric & 30 & 6 & 80.0 & 21 & 0 & 9 \\
\hline Chia ${ }^{47} 2017$ & Retrospective cohort & Mixed & 1554 & 38 & 97.6 & NR & NR & 1554 \\
\hline Chiang eta $/{ }^{48} 2015$ & Retrospective cohort & Adult & 514 & 20 & 96.1 & 388 & 0 & 126 \\
\hline Chien $^{49} 2016$ & Retrospective cohort & Adult & 396 & 9 & 97.7 & 197 & 11 & 188 \\
\hline David 2007 & Retrospective cohort & Adult & 268 & 6 & 97.8 & NR & NR & 268 \\
\hline Deasy $^{51} 2012$ & Retrospective cohort & Mixed & 2187 & 28 & 98.7 & NR & NR & 2187 \\
\hline Di Bartolomeo ${ }^{19} 2005$ & Retrospective cohort & Adult & 181 & 2 & 89.0 & 181 & 0 & 0 \\
\hline Djarv 522018 & Retrospective cohort & Mixed & 1774 & 65 & 96.3 & NR & $\mathrm{NR}$ & 1774 \\
\hline Duchateau ${ }^{53} 2017$ & Retrospective cohort & Adult & 88 & 10 & 88.6 & 77 & 11 & 0 \\
\hline Evans $^{5} 2016$ & Retrospective cohort & Mixed & 2300 & 145 & 92.7 & 1547 & 736 & 270 \\
\hline Falcone $e^{54} 1995$ & Retrospective cohort & Adult & 320 & 6 & 98.1 & 285 & 36 & 0 \\
\hline Fisher ${ }^{55} 1999$ & Retrospective cohort & Pediatric & 65 & 1 & 98.5 & 65 & 0 & 0 \\
\hline Graesner $^{56} 2011$ & Retrospective cohort & Mixed & 814 & 221 & 72.9 & 597 & 52 & 165 \\
\hline Hillman ${ }^{57} 2016$ & Retrospective cohort & Pediatric & 27 & 4 & 85.2 & 4 & 7 & 16 \\
\hline Huber-Wagner ${ }^{58} 2007$ & Retrospective cohort & Mixed & 757 & 130 & 82.8 & 714 & 43 & 0 \\
\hline Keller $^{37} 2013$ & Retrospective cohort & Mixed & 448 & 37 & 91.7 & NR & NR & NR \\
\hline Kleber ${ }^{23} 2014$ & Prospective cohort & Mixed & 71 & 15 & 79.9 & 40 & 12 & 19 \\
\hline Lawhon ${ }^{20} 1995$ & Retrospective cohort & Mixed & 47 & 2 & 95.7 & NR & NR & 47 \\
\hline $\operatorname{Lin}^{59} 2016$ & Retrospective cohort & Pediatric & 388 & 38 & 91.2 & 365 & 23 & 0 \\
\hline Love $^{60} 2016$ & Retrospective cohort & Mixed & 237 & 7 & 97.0 & 165 & 72 & 0 \\
\hline Lundy ${ }^{61} 2011$ & Retrospective cohort & Mixed & 309 & 125 & 59.5 & NR & NR & 309 \\
\hline Molina $^{62} 2008$ & Retrospective cohort & Mixed & 94 & 8 & 91.5 & 0 & 94 & 0 \\
\hline Mollberg 2011 & Retrospective cohort & Adult & 294 & 1 & 99.7 & 90 & 204 & 0 \\
\hline Moore $^{44} 2011$ & Prospective cohort & Mixed & NR & 56 & NR & 5 & 51 & NR \\
\hline Moore $^{64} 2016$ & Prospective cohort & Adult & 1708 & 106 & 93.8 & 820 & 888 & 0 \\
\hline Murphy5 2010 & Retrospective cohort & Pediatric & 169 & 28 & 83.4 & 151 & 7 & 11 \\
\hline Perron ${ }^{66} 2001$ & Retrospective cohort & Pediatric & 729 & 184 & 74.8 & 505 & 81 & 143 \\
\hline Pickens ${ }^{67} 2005$ & Retrospective cohort & Mixed & 184 & 14 & 92.4 & 90 & 94 & 0 \\
\hline Powell ${ }^{68} 2004$ & Retrospective cohort & Mixed & 959 & 62 & 93.5 & 11 & 51 & 897 \\
\hline Rabinovici' 2014 & Retrospective cohort & Mixed & 67 & 9 & 86.6 & 17 & 50 & 0 \\
\hline Shimazuo 1983 & Retrospective cohort & Mixed & 267 & 7 & 97.4 & 217 & 50 & 0 \\
\hline Stratton 1998 & Retrospective cohort & Mixed & 879 & 9 & 99.9 & 382 & 497 & 0 \\
\hline Tarmey $^{43} 2011$ & Prospective cohort & Adult & 52 & 4 & 92.3 & 0 & 17 & 35 \\
\hline Vassallo 2019 & Retrospective cohort & Pediatric & 129 & 7 & 94.6 & 110 & 19 & 0 \\
\hline Zwingmann ${ }^{73} 2015$ & Retrospective cohort & Pediatric & 152 & 43 & 71.7 & 145 & 7 & 0 \\
\hline Zwingmann ${ }^{21} 2016$ & Retrospective cohort & Mixed & 3052 & 649 & 78.7 & NR & NR & 3052 \\
\hline
\end{tabular}

NR, not reported. 


\section{Patient characteristics}

There were 23644 patients included, with 2168 (9.2\%) surviving to hospital discharge. The mortality rate was $90.8 \%$. Blunt trauma ( $n=8687$ patients) and penetrating trauma $(n=3489$ patients) were the main mechanisms of traumatic arrest, whereas the remaining trauma mechanisms were not classified $(n=11$ 468) (table 1). Nine studies examined pediatric patients only $(n=1714$ patients), 9 studies examined adults only $(n=3821$ patients), and 22 studies examined a mixed population $(n=18$ 109 patients) without providing information of how many pediatric patients were included.

\section{Neurological outcome reporting}

Seventeen studies qualitatively described their neurological outcome based on patient disposition after discharge (eg, home, nursing care, or rehabilitation) and the level of assistance required in daily activities. Thirteen studies used the GOS and reported the number of patients in each GOS category (GOS 1-5). Eight studies used the CPC and one study used the Pediatric Cerebral Performance Categories (PCPC) to assess neurological outcome.

Seven studies dichotomized neurological outcomes into "good" or "poor" categories using the GOS, CPC, or PCPC scales. Six of the seven studies considered a "good" neurological outcome as patients with CPC 1 and 2 or GOS 4 and 5 (ie, good, mild, or moderate deficits) and a "poor" neurological outcome as those with CPC 3 and 5 or GOS 1 and 3 (ie, severe or vegetative). One study used the PCPC and defined a "good" outcome as PCPC 1 and 2 (good or mild deficits) and a "poor" outcome as PCPC 3 and 5 (moderate or severe deficits, or vegetative).

One study used the FIM to assess neurological status. This study reported an average FIM score for the survivors and the number of patients who had obtained the lowest score (required assistance in daily life). The functional status of the other patients was not reported.

Neurological status was recorded primarily at patient discharge, but some studies reported outcomes up to a 4-year follow-up period.

\section{Overall neurological outcomes}

The neurological outcomes of individual studies are reported in table 2 . Based on the 32 studies ( $n=1507$ patients) that reported the number of patients for each neurological outcome category, $538(35.7 \%)$ had good outcomes, 392 (26.0\%) had moderate outcomes, $408(27.1 \%)$ had poor outcomes, and $169(11.2 \%)$ were vegetative.

In six studies ( $\mathrm{n}=115$ patients) that reported dichotomous outcomes, 62 patients (53.9\%) had "good" outcomes and 53 patients $(46.1 \%)$ had "poor" outcomes. In the one study $(n=38$ patients) that used the PCPC, 12 (31.6\%) had "good" outcomes and $26(68.4 \%)$ had "poor" outcomes. One study $(n=184$ patients) that used the FIM reported an average score of 38.9 (range: 18-126), 7 patients with severe deficits and 177 patients that had either good recovery or moderate or severe deficits.

Based on all 40 studies ( $n=2168$ patients) included in this review, 992 (45.8\%) had favorable outcomes, 630 (29.0\%) had unfavorable outcomes, and $546(25.2 \%)$ were missing. The results of the studies that used the PCPC and the FIM were included in the missing category, as the neurological status of the survivors was unclear and could not be categorized.

\section{Neurological outcomes for pediatric studies}

Of the seven studies ( $n=87$ patients) that examined only pediatric populations and reported the number of patients for each neurological outcome category, 37 (42.5\%) had good outcomes, $19(21.8 \%)$ had moderate outcomes, 18 (20.7\%) had poor outcomes, and 13 (14.9\%) were vegetative. Hence, 56 patients $(64.4 \%)$ had favorable outcomes and 31 (35.6\%) had unfavorable outcomes.

\section{Neurological outcomes for adult studies}

Of the nine studies ( $\mathrm{n}=164$ patients) that examined only adult populations, 119 patients $(72.6 \%)$ had favorable outcomes, 41 (25.0\%) had unfavorable outcomes, and 4 (2.4\%) had missing outcomes. Of the six studies $(n=129$ patients) that reported the number of patients for each neurological outcome category, $87(67.4 \%)$ had good outcomes, 15 (11.6\%) had moderate outcomes, $6(4.7 \%)$ had poor outcomes, 17 (13.2\%) were vegetative, and 4 (3.1\%) had missing outcomes.

\section{Assessment of quality}

The quality of all included studies ( $\mathrm{n}=40$ studies) was assessed. Twenty-eight studies were at a serious risk of bias and 12 studies were at a moderate risk of bias (table 3). In general, the studies were well reported. The confounding domain was the primary source of bias, as most studies did not consider many potential confounders, including age, resuscitation technique, and type of trauma. The outcome measurement domain was also a significant source of bias, as most studies used physician-reported neurological outcomes, which were described qualitatively in the studies. Hence, these studies were rated as a serious risk of bias in this domain. Finally, there was moderate to serious risk of bias for selective reporting, as some studies did not report outcomes for each neurological category.

\section{DISCUSSION}

The current review is the first study to focus on neurological outcomes across a large patient population ( $n=23644$ patients). We report a survival rate of $9.2 \%$, which is one of the most optimistic findings to date for outcomes following TCA. In the current review, favorable neurological outcomes were frequently reported (45.8\% with full recovery or moderate disability), suggesting that outcomes from TCA may be more favorable than previously expected. ${ }^{3}$

Previous literature suggests that prognosis after traumatic arrest is extremely poor. Many studies reported only a small number of survivors, all with severe neurological disability. ${ }^{3141920}$ However, in 2012, new studies were conducted and a systematic review found that good and moderate neurological outcomes were reported in $57.4 \%$ of survivors. ${ }^{15}$ A large retrospective study published in 2016 supports these findings and reported good and moderate neurological outcomes in up to $75.0 \%$ of survivors. ${ }^{21}$ Despite these findings, neurological outcomes continue to be debated, as newer studies with larger numbers of survivors report good and moderate outcomes in only $4.3 \%$ to $27.0 \%$ of survivors. $^{22} 23$ The findings of the current review suggest that those who survive traumatic arrest may have a favorable prognosis. The observed improvement in neurological outcomes is likely connected to novel advances in damage control resuscitation and refinement of treatment of guidelines. ${ }^{7}$

A secondary aim of this review was to assess the quality of the reporting of neurological outcomes. In most of the included studies, neurological status was qualitatively described. As the exact deficits were often not described, it was difficult to quantify the extent of the impairments and classify the neurological outcomes of these patients. Alternatively, patient disposition (eg, home, nursing care, rehabilitation) and dependence 
Table 2 Neurological outcomes of included studies

\begin{tabular}{|c|c|c|c|c|c|c|c|}
\hline \multirow[b]{2}{*}{ Study identification } & \multirow[b]{2}{*}{ Neurological scale } & \multirow[b]{2}{*}{ Time point } & \multicolumn{4}{|c|}{ Qualitative outcomes } & \multirow[b]{2}{*}{ Missing } \\
\hline & & & Good & Moderate & Poor & Vegetative & \\
\hline Alanezi ${ }^{45} 2004$ & Qualitative & Discharge & 1 & 0 & 1 & 0 & 0 \\
\hline Barnard 2017 & GOS & Discharge & $24^{*}$ & $\mathrm{~N} / \mathrm{A}$ & $9 \dagger$ & $\mathrm{N} / \mathrm{A}$ & 20 \\
\hline Beck $^{46} 2016$ & CPC & Discharge & $6^{*}$ & N/A & 3 & 0 & 0 \\
\hline Calkins $^{34} 2002$ & Qualitative & Discharge & 2 & 0 & 0 & 0 & 0 \\
\hline Capizzani35 2010 & Qualitative & Discharge & 2 & 1 & 3 & 0 & 0 \\
\hline Chiang $^{48} 2015$ & CPC & Discharge & $12^{*}$ & $\mathrm{~N} / \mathrm{A}$ & $8+$ & $\mathrm{N} / \mathrm{A}$ & 0 \\
\hline Chien ${ }^{49} 2016$ & CPC & Discharge & $3^{*}$ & $N / A$ & $6 t$ & $\mathrm{~N} / \mathrm{A}$ & 0 \\
\hline David $^{50} 2007$ & CPC & Discharge & $2^{*}$ & N/A & $4 \dagger$ & N/A & 0 \\
\hline Deasy $^{51} 2012$ & GOS & 1 year & 0 & 2 & 2 & 1 & 23 \\
\hline Di Bartolomeo ${ }^{19} 2005$ & GOS & 4 years & 0 & 0 & 2 & 0 & 0 \\
\hline Falcone $e^{54} 1995$ & Qualitative & Discharge & 4 & 0 & 2 & 0 & 0 \\
\hline Fisher ${ }^{55} 1999$ & Qualitative & Discharge & 0 & 0 & 0 & 1 & 0 \\
\hline Graesner $^{56} 2011$ & GOS & Discharge & 72 & 53 & 48 & 40 & 8 \\
\hline Hillman ${ }^{57} 2016$ & Qualitative & Variable & 1 & 0 & 1 & 0 & 2 \\
\hline Huber-Wagner ${ }^{58} 2007$ & GOS & Discharge & 15 & 13 & 15 & 6 & 81 \\
\hline Keller $^{37} 2013$ & GOS & Variable & 12 & 2 & 2 & 1 & 20 \\
\hline Kleber $^{23} 2014$ & GOS & Discharge & 1 & 3 & 10 & 1 & 0 \\
\hline Lawhon 201995 & Qualitative & Discharge/3 years & 0 & 0 & 1 & 1 & 0 \\
\hline $\operatorname{Lin}^{59} 2016$ & PCPC & Discharge & 12 & $26 \ddagger$ & $N / A$ & $\mathrm{~N} / \mathrm{A}$ & 0 \\
\hline Love $^{60} 2016$ & Qualitative & Discharge & 4 & 0 & 3 & 0 & 0 \\
\hline Pickens $^{67} 2005$ & Qualitative & Discharge & 11 & 1 & 0 & 2 & 0 \\
\hline Powell|68 2004 & Qualitative & Discharge & 15 & 6 & 5 & 0 & 36 \\
\hline Rabinovici ${ }^{69} 2014$ & Qualitative & Discharge & 7 & 1 & 1 & 0 & 0 \\
\hline Shimazu ${ }^{70} 1983$ & Qualitative & 30 days post admission & 4 & 0 & 2 & 0 & 1 \\
\hline Stratton 711998 & CPC & Discharge & 3 & 1 & 2 & 3 & 0 \\
\hline Tarmey $^{43} 2011$ & GOS & Discharge & 4 & 0 & 0 & 0 & 0 \\
\hline Vassallo 2019 & GOS & Discharge/30 days & 2 & 2 & 1 & 0 & 2 \\
\hline Zwingmann³ 2015 & GOS & After resuscitation & 14 & 13 & 6 & 10 & 0 \\
\hline Zwingmann ${ }^{21} 2016$ & GOS & After resuscitation & 193 & 201 & 174 & 81 & 0 \\
\hline Total & & Favorable: 992 & & & Unfav & & Missing: 546 \\
\hline
\end{tabular}

${ }^{*}$ Reported as good or moderate.

tReported as poor or vegetative.

†Reported as moderate, poor, or vegetative.

$\S$ Reported as good, moderate, or poor.

CPC, Cerebral Performance Categories; FIM, Functional Independence Measure; GOS, Glasgow Outcome Scale; N/A, not available; PCPC, Pediatric Cerebral Performance Categories.

on daily support had to be used as indicators of neurological status. Furthermore, as an outcome measurement scale was not used, there is likely some degree of variation and biases among physician-reported outcomes. Several included studies reported dichotomous outcomes using a standardized scale by combining CPC 1 to 2 (good and moderate) as a "good" outcome and
CPC 3 to 5 (severe, vegetative, death) as a "poor" outcome. However, the definition of a "good" and "poor" outcome varied between studies as CPC 3 was historically considered a "good" outcome. ${ }^{24}$ This reflects the differing values and preferences in the evaluation of neurological outcomes after arrest; therefore, reporting the exact deficits of the survivors is a key component 
Table 3 Quality review of included studies

\begin{tabular}{|c|c|c|c|c|c|c|c|c|}
\hline Study identification & Confounding* & $\begin{array}{l}\text { Participant } \\
\text { selectiont }\end{array}$ & $\begin{array}{l}\text { Classification of } \\
\text { interventions }\end{array}$ & $\begin{array}{l}\text { Deviation } \\
\text { from intended } \\
\text { interventions§ }\end{array}$ & $\begin{array}{l}\text { Missing } \\
\text { dataf }\end{array}$ & Outcomes** & $\begin{array}{l}\text { Selective } \\
\text { reportingtt }\end{array}$ & Overall bias \\
\hline Alanezi45 2004 & Serious & Moderate & Low & Moderate & Low & Serious & Moderate & Serious \\
\hline Barnard4 2017 & Serious & Moderate & Low & Moderate & Moderate & Moderate & Moderate & Serious \\
\hline Beck $^{46} 2016$ & Moderate & Moderate & Low & Low & Moderate & Moderate & Moderate & Moderate \\
\hline Calkins ${ }^{34} 2002$ & Serious & Low & Low & Low & Low & Serious & Moderate & Serious \\
\hline Capizzani35 2010 & Moderate & Low & Low & Low & Low & Serious & Moderate & Serious \\
\hline Chia ${ }^{47} 2017$ & Moderate & Low & Low & Moderate & Low & Moderate & Moderate & Moderate \\
\hline Chiang $^{48} 2015$ & Moderate & Low & Low & Moderate & Low & Moderate & Low & Moderate \\
\hline Chien $^{49} 2016$ & Serious & Low & Low & Low & Moderate & Moderate & Moderate & Serious \\
\hline David $^{50} 2007$ & Moderate & Low & Low & Moderate & Low & Moderate & Moderate & Moderate \\
\hline Deasy ${ }^{51} 2012$ & Moderate & Low & Low & Low & Serious & Moderate & Moderate & Serious \\
\hline Di Bartolomeo ${ }^{19} 2005$ & Serious & Low & Low & Low & Low & Moderate & Moderate & Serious \\
\hline Djarv 2018 & Moderate & Low & Low & Low & Serious & Moderate & Moderate & Serious \\
\hline Duchateau 2017 & Moderate & Low & Low & Low & Low & Moderate & Moderate & Moderate \\
\hline Evans $^{44} 2016$ & Moderate & Low & Low & Low & Moderate & Moderate & Moderate & Moderate \\
\hline Falcone $e^{54} 1995$ & Serious & Low & Low & Moderate & Low & Serious & Moderate & Serious \\
\hline Fisher ${ }^{55} 1999$ & Serious & Low & Low & Moderate & Low & Serious & Moderate & Serious \\
\hline Graesner $^{56} 2011$ & Moderate & Low & Low & Moderate & Moderate & Moderate & Moderate & Moderate \\
\hline Hillman ${ }^{57} 2016$ & Serious & Moderate & Low & Moderate & Serious & Serious & Moderate & Serious \\
\hline Huber-Wagner ${ }^{58} 2007$ & Moderate & Moderate & Low & Moderate & Serious & Moderate & Moderate & Serious \\
\hline Keller $^{37} 2013$ & Serious & Serious & Low & Low & Serious & Moderate & Moderate & Serious \\
\hline Kleber $^{23} 2014$ & Serious & Low & Low & Moderate & Low & Moderate & Moderate & Serious \\
\hline Lawhon ${ }^{20} 1995$ & Serious & Low & Low & Low & Low & Serious & Moderate & Serious \\
\hline $\operatorname{Lin}^{59} 2016$ & Moderate & Moderate & Low & Low & Low & Moderate & Moderate & Moderate \\
\hline Love $^{60} 2016$ & Moderate & Low & Low & Moderate & Low & Serious & Moderate & Serious \\
\hline Lundy ${ }^{61} 2011$ & Moderate & Moderate & Low & Moderate & Low & Moderate & Moderate & Moderate \\
\hline Molina $^{62} 2008$ & Serious & Low & Low & Low & Low & Serious & Moderate & Serious \\
\hline Mollberg ${ }^{63} 2011$ & Serious & Low & Low & Moderate & Low & Serious & Moderate & Serious \\
\hline Moore $^{64} 2011$ & Moderate & Low & Low & Low & Low & Moderate & Moderate & Serious \\
\hline Moore ${ }^{44} 2016$ & Moderate & Low & Low & Low & Low & Moderate & Moderate & Moderate \\
\hline Murphy 2010 & Serious & Low & Low & Low & Low & Serious & Moderate & Serious \\
\hline Perron ${ }^{66} 2001$ & Moderate & Low & Low & Low & Serious & Moderate & Serious & Serious \\
\hline Pickens $^{67} 2005$ & Moderate & Moderate & Low & Low & Low & Moderate & Moderate & Moderate \\
\hline Powell ${ }^{68} 2004$ & Serious & Serious & Low & Low & Low & Moderate & Moderate & Serious \\
\hline Rabinovici69 2014 & Moderate & Low & Low & Low & Low & Serious & Moderate & Serious \\
\hline Shimazu 1983 & Serious & Moderate & Moderate & Low & Low & Serious & Moderate & Serious \\
\hline Stratton 1998 & Moderate & Low & Low & Low & Low & Moderate & Moderate & Moderate \\
\hline Tarmey $^{43} 2011$ & Serious & Low & Low & Moderate & Low & Moderate & Moderate & Serious \\
\hline Vassallo 722019 & Serious & Moderate & Low & Low & Moderate & Moderate & Moderate & Serious \\
\hline Zwingmann ${ }^{73} 2015$ & Moderate & Serious & Low & Low & Low & Moderate & Moderate & Serious \\
\hline Zwingmann²1 2016 & Moderate & Serious & Moderate & Moderate & Low & Moderate & Moderate & Serious \\
\hline
\end{tabular}

*Were confounding variables controlled for with statistical analysis (eg, multivariate analysis)? Did they determine these factors appropriately (eg, univariate analysis, references, subject matter expert, etc)?

tWere only survivors/non-vegetative participants assessed? Was any group excluded (eg, specific year of arrests, no rhythm on presentation, type of trauma, witnessed cardiac arrest only, etc)?

¥Was the exposure (traumatic cardiac arrest) well defined before the study? Was there a method used to identify these cases?

$\S$ Were special methods used for resuscitation (eg, therapeutic hypothermia, thoracotomy)? If so, was it reported and appropriately accounted for?

IWere any patients lost to follow-up? Was any method used to account for this/any attempt made to recover from this? Was there a particular group of patients that were lost

to follow-up?

**Was the exposure known to the person assessing neurological outcome? How were neurological outcomes assessed? Was it subjective/unclear (eg, physician-reported, selfreported, etc)? Was a standardized scale used and data reported for all categories (eg, Glasgow Outcome Scale)?

††Was there a preregistered protocol with preplanned outcomes to report? Were only specific outcomes reported in full? Were the neurological outcomes dichotomized into "good" and "poor" instead of reporting for each category? 
of their neuroprognostication, as there may be a large difference between a moderate disability and a fully recovered patient.

Although the GOS and CPC scales were commonly used, alternatives such as the mRS and the GOSE were not used in any of the included studies. The CPC is heavily weighted toward mental functions and has been criticized for being inadequate to assess functional status at hospital discharge, ${ }^{25} 26$ which is supported by significant variability in quality-of-life measures for patients with similar CPC scores. ${ }^{27}{ }^{28}$ Alternatively, the mRS and GOSE scales consider work capacities, social activities, and return to social life. ${ }^{11}{ }^{29}$ However, most studies assessed neurological status at discharge, which may be inadequate regardless of the scale used. Most criteria rely on whether patients can perform daily activities, which are not undertaken while in hospital. ${ }^{11}$ As cardiac arrest survivors tend to report cognitive impairment and restricted societal participation after hospital discharge, ${ }^{30}$ early assessments may overestimate the neurological outcomes. Hence, repeated assessments over time with multiple scales are recommended to accurately assess the functional progression of these patients.

This review has several limitations. To start, our overall neurological outcome may be an overestimate given that patients with moderate deficits and favorable discharge dispositions were assumed to have a favorable outcome. Furthermore, the favorable neurological recovery rate that we provide here is based on a diverse patient population and does not account for the mechanism of trauma (blunt vs. penetrating), the patient age group (adult vs. pediatric), the time point when neurological status is assessed, or special resuscitative techniques. Previous literature has demonstrated varying effects of these factors in neurological outcomes. The effect of the mechanism of injury on traumatic arrest outcomes has been controversial. Whereas some cohort studies suggest that good outcomes can be achieved in select patient groups, especially in those with penetrating injuries, ${ }^{31} 32$ other studies suggest that the mechanism of injury is not associated with better outcomes (neurological recovery or survival). ${ }^{2233}$ Hence, it would be valuable to assess the effect of the mechanism of injury on the neurological recovery following arrest. Although only a few studies assess traumatic arrest in the pediatric population, there is a general consensus that the functional outcomes are poorer compared with adults. ${ }^{15} 3435$ In the length of follow-up after cardiac arrest, there is evidence that significant recovery can occur between 1 and 6 months $^{36}$ and long-term recovery after 1 year. ${ }^{37}$ The majority of the studies we included assessed neurological outcomes at patient discharge or after resuscitation (table 2), suggesting that we underestimated the prevalence of good neurological recovery in the current review. Special resuscitative techniques, such as emergency thoracotomy and therapeutic hypothermia, have some demonstrated benefits in neurological outcomes after traumatic arrest for select patient populations. ${ }^{38-42}$ Based on the effects of these factors on neurological recovery, we recommend for future studies evaluating outcomes after traumatic arrest (1) reporting the mechanism of injury for survivors in each neurological outcome category, (2) reporting the age group (adult vs. pediatric) in each neurological outcome category, (3) assessing neurological outcomes 1 year after the arrest if resources allow or $>30$ days if necessary, ${ }^{36}$ and (4) reporting special resuscitative techniques in individual survivors in each neurological outcome category.

Overall, the strength of the scientific evidence for neurological outcomes after TCA is low. Although we identified some large national registry studies, most studies were retrospective cohorts. ${ }^{45} 43$ Five prospective studies were included, but only one was a multicenter study. ${ }^{44}$ Furthermore, our quality assessment revealed a moderate to serious risk of bias in our included studies due to confounding and selective reporting domains. Our outcome of interest was often qualitatively described, and some studies briefly reported neurological outcomes for only one category (eg, vegetative state). As a result, many studies without sufficient data were excluded, and the extent of the selective reporting bias we identified may be an underestimate.

Good and moderate neurological outcomes are frequently reported in patients who survive TCA. However, stronger evidence is needed to prognosticate this patient population as neurological outcomes are often inadequately reported. Future studies should identify and adjust for appropriate confounding variables and report the prevalence of each neurological category. Multicenter prospective studies that focus on the quality of survivorship are urgently needed.

Acknowledgements We thank Si Hong Yu (Health Sciences Librarian at Queen's University) for his help with the development of the search strategy.

Contributors DS, CM, and CE conceived the study design. DS and CM created the literature search. DS and CM collected data and conducted the quality assessment with assistance from CE. DS drafted the article. CM prepared the figure and tables, and all authors contributed substantially to revision. All authors take responsibility for the article as a whole. DS is the guarantor of the article and accepts responsibility for the integrity of the published work.

Funding External funding was received from the Queen's Department of Emergency Medicine in the Emergency Medicine Summer Studentship Award (DS and CM).

Competing interests None declared.

Patient consent for publication Not required.

Provenance and peer review Not commissioned; externally peer reviewed.

Open access This is an open access article distributed in accordance with the Creative Commons Attribution Non Commercial (CC BY-NC 4.0) license, which permits others to distribute, remix, adapt, build upon this work non-commercially, and license their derivative works on different terms, provided the original work is properly cited, appropriate credit is given, any changes made indicated, and the use is non-commercial. See: http://creativecommons.org/licenses/by-nc/4.0/.

\section{REFERENCES}

1 Kauvar DS, Lefering R, Wade CE. Impact of hemorrhage on trauma outcome: an overview of epidemiology, clinical presentations, and therapeutic considerations. J Trauma 2006;60:S3-11.

2 Millin MG, Galvagno SM, Khandker SR, Malki A, Bulger EM, . Standards and Clinical Practice Committee of the National Association of EMS Physicians (NAEMSP)Subcommittee on Emergency Services-Prehospital of the American College of Surgeons' Committee on Trauma (ACSCOT). Withholding and termination of resuscitation of adult cardiopulmonary arrest secondary to trauma: resource document to the joint NAEMSP-ACSCOT position statements. J Trauma Acute Care Surg 2013;75:459-67.

3 Rosemurgy AS, Norris PA, Olson SM, Hurst JM, Albrink MH. Prehospital traumatic cardiac arrest: the cost of futility. J Trauma 1993;35:468-72.

4 Barnard E, Yates D, Edwards A, Fragoso-Iñiguez M, Jenks T, Smith JE. Epidemiology and aetiology of traumatic cardiac arrest in England and Wales - A retrospective database analysis. Resuscitation 2017;110:90-4.

5 Evans CCD, Petersen A, Meier EN, Buick JE, Schreiber M, Kannas D, Austin MA, Resuscitation Outcomes Consortium Investigators. Prehospital traumatic cardiac arrest: management and outcomes from the resuscitation outcomes Consortium epistry-trauma and PROPHET registries. J Trauma Acute Care Surg 2016;81:285-93.

6 Leis CC, Hernández CC, Blanco MJG-0, Paterna PCR, Hernández RdeE, Torres EC. Traumatic cardiac arrest: should advanced life support be initiated? J Trauma Acute Care Surg 2013;74:634-8.

7 Smith JE, Rickard A, Wise D. Traumatic cardiac arrest. J R Soc Med 2015; 108:11-16.

8 Kim Y-J, Ahn S, Sohn CH, Seo D-W, Lee Y-S, Lee JH, Oh BJ, Lim KS, Kim WY. Long-Term neurological outcomes in patients after out-of-hospital cardiac arrest. Resuscitation 2016;101:1-5.

9 Sandroni C, D'Arrigo S, Nolan JP. Prognostication after cardiac arrest. Crit Care 2018:22:150.

10 Hofgren C, Lundgren-Nilsson A, Esbjörnsson E, Sunnerhagen KS. Two years after cardiac arrest; cognitive status, ADL function and living situation. Brain Inj 2008;22:972-8.

11 Rittenberger JC, Raina K, Holm MB, Kim YJ, Callaway CW. Association between cerebral performance category, modified Rankin scale, and discharge disposition after cardiac arrest. Resuscitation 2011;82:1036-40. 
12 Weir J, Steyerberg EW, Butcher I, Lu J, Lingsma HF, McHugh GS, Roozenbeek B, Maas AIR, Murray GD. Does the extended Glasgow outcome scale add value to the conventional Glasgow outcome scale? J Neurotrauma 2012;29:53-8

13 Battistella FD, Nugent W, Owings JT, Anderson JT. Field triage of the pulseless trauma patient. Arch Surg 1999;134:742.

14 Martin SK, Shatney CH, Sherck JP, Ho C-C, Homan SJ, Neff J, Moore EE. Blunt trauma patients with prehospital pulseless electrical activity (pea): poor ending assured. J Trauma 2002:53:876-81.

15 Zwingmann J, Mehlhorn AT, Hammer T, Bayer J, Südkamp NP, Strohm PC. Survival and neurologic outcome after traumatic out-of-hospital cardiopulmonary arrest in a pediatric and adult population: a systematic review. Crit Care 2012;16:R117.

16 Higgins JPT, Altman DG, Gøtzsche PC, Jüni P, Moher D, Oxman AD, Savovic J, Schulz KF, Weeks L, Sterne JAC, et al. The Cochrane collaboration's tool for assessing risk of bias in randomised trials. BMJ 2011;343:d5928.

17 Veritas Health Innovation. Covidence systematic review software. Melbourne, Australia: Veritas Health Innovation, 2019.

18 McHugh ML. Interrater reliability: the kappa statistic. Biochem Med 2012;22:276-82

19 Di Bartolomeo S, Sanson G, Nardi G, Michelutto V, Scian F. Hems vs. Ground-BLS care in traumatic cardiac arrest. Prehosp Emerg Care 2005;9:79-84.

20 Lawhon JC, Somberg LB, Barker DE. Prehospital blunt traumatic arrest: survival and analysis. J Tenn Med Assoc 1995;88:4.

21 Zwingmann J, Lefering R, Feucht M, Südkamp NP, Strohm PC, Hammer T. Outcome and predictors for successful resuscitation in the emergency room of adult patients in traumatic cardiorespiratory arrest. Crit Care 2016;20:282.

22 Kim JG, Lee J, Choi HY, Kim W, Kim J, Moon S, Shin H, Ahn C, Cho Y, Shin DG, et al. Outcome analysis of traumatic out-of-hospital cardiac arrest patients according to the mechanism of injury: a nationwide observation study. Medicine 2020;99:e23095.

23 Kleber C, Giesecke MT, Lindner T, Haas NP, Buschmann CT. Requirement for a structured algorithm in cardiac arrest following major trauma: epidemiology, management errors, and preventability of traumatic deaths in Berlin. Resuscitation 2014;85:405-10.

24 Sandroni C, Nolan JP. Neuroprognostication after cardiac arrest in Europe: new timings and standards. Resuscitation 2015;90:A4-5.

25 Cummins RO, Chamberlain D, Hazinski MF, Nadkarni V, Kloeck W, Kramer E, Becker L, Robertson C, Koster R, Zaritsky A, et al. Recommended guidelines for reviewing, reporting, and conducting research on in-hospital resuscitation: the in-hospital "Utstein style". American Heart Association. Ann Emerg Med 1997;29:650-79.

$26 \mathrm{Hsu}^{*}$ JWY, Madsen§ CD, Callaham ML. Quality-Of-Life and formal functional testing of survivors of out-of-hospital cardiac arrest correlates poorly with traditional neurologic outcome scales. Ann Emerg Med 1996;28:597-605.

27 Raina KD, Callaway C, Rittenberger JC, Holm MB. Neurological and functional status following cardiac arrest: method and tool utility. Resuscitation 2008;79:249-56.

28 Stiell IG, Nesbitt LP, Nichol G, Maloney J, Dreyer J, Beaudoin T, Blackburn J, Wells GA, OPALS Study Group. Comparison of the cerebral performance category score and the health Utilities index for survivors of cardiac arrest. Ann Emerg Med 2009;53:241-8.

29 Teasdale GM, Pettigrew LE, Wilson JT, Murray G, Jennett B. Analyzing outcome of treatment of severe head injury: a review and update on advancing the use of the Glasgow outcome scale. J Neurotrauma 1998;15:587-97.

30 Haywood K, Whitehead L, Nadkarni VM, Achana F, Beesems S, Böttiger BW, Brooks A, Castrén M, Ong ME, Hazinski MF, et al. COSCA (core outcome set for cardiac arrest) in adults: an Advisory statement from the International liaison Committee on resuscitation. Circulation 2018:137:e783-801.

31 Dane FC, Russell-Lindgren KS, Parish DC, Durham MD, Brown TD. In-Hospital resuscitation: association between ACLS training and survival to discharge. Resuscitation 2000;47:83-7.

32 Davies GE, Lockey DJ. Thirteen survivors of prehospital thoracotomy for penetrating trauma: a prehospital physician-performed resuscitation procedure that can yield good results. J Trauma 2011;70:E75-8

33 Tran A, Fernando SM, Rochwerg B, Vaillancourt C, Inaba K, Kyeremanteng K, Nolan JP, McCredie VA, Petrosoniak A, Hicks C, et al. Pre-arrest and intraarrest prognostic factors associated with survival following traumatic out-ofhospital cardiac arrest - A systematic review and meta-analysis. Resuscitation 2020;153:119-35.

34 Calkins CM, Bensard DD, Partrick DA, Karrer FM. A critical analysis of outcome for children sustaining cardiac arrest after blunt trauma. J Pediatr Surg 2002;37:180-4.

35 Capizzani AR, Drongowski R, Ehrlich PF. Assessment of termination of trauma resuscitation guidelines: are children small adults? J Pediatr Surg 2010;45:903-7.

36 Geocadin RG, Callaway CW, Fink EL, Golan E, Greer DM, Ko NU, Lang E, Licht DJ, Marino BS, McNair ND, et al. Standards for studies of neurological prognostication in comatose survivors of cardiac arrest: a scientific statement from the American heart association. Circulation 2019;140:e517-42.

37 Keller D, Kulp H, Maher Z, Santora TA, Goldberg AJ, Seamon MJ. Life after near death: long-term outcomes of emergency department thoracotomy survivors. J Trauma Acute Care Surg 2013;74:1315-20.

38 Baker CC, Caronna JJ, Trunkey DD. Neurologic outcome after emergency room thoracotomy for trauma. Am J Surg 1980;139:677-81.

39 Hughes M, Perkins Z. Outcomes following resuscitative thoracotomy for abdominal exsanguination, a systematic review. Scand J Trauma Resusc Emerg Med 2020;28:9.
40 Seamon MJ, Haut ER, Van Arendonk K, Barbosa RR, Chiu WC, Dente CJ, Fox N, Jawa RS, Khwaja K, Lee JK, et al. An evidence-based approach to patient selection for emergency department thoracotomy: a practice management guideline from the eastern association for the surgery of trauma. J Trauma Acute Care Surg 2015;79:159-73.

41 Song SS, Lyden PD. Overview of therapeutic hypothermia. Curr Treat Options Neurol 2012;14:541-8.

42 Tuma MA, Stansbury LG, Stein DM, McQuillan KA, Scalea TM. Induced hypothermia after cardiac arrest in trauma patients: a case series. J Trauma 2011;71:1524-7.

43 Tarmey NT, Park CL, Bartels OJ, Konig TC, Mahoney PF, Mellor AJ. Outcomes following military traumatic cardiorespiratory arrest: a prospective observational study. Resuscitation 2011;82:1194-7.

44 Moore EE, Knudson MM, Burlew CC, Inaba K, Dicker RA, Biffl WL, Malhotra AK, Schreiber MA, Browder TD, Coimbra R, et al. Defining the limits of resuscitative emergency department thoracotomy: a contemporary Western trauma association perspective. J Trauma 2011;70:334-9.

45 Alanezi K, Alanzi F, Faidi S, Sprague S, Cadeddu M, Baillie F, Bowser D, McCallum A Bhandari M. Survival rates for adult trauma patients who require cardiopulmonary resuscitation. CJEM 2004:6:263-5.

46 Beck B, Tohira H, Bray JE, Straney L, Brown E, Inoue M, Williams TA, McKenzie N, Celenza A, Bailey P, et al. Trends in traumatic out-of-hospital cardiac arrest in Perth, Western Australia from 1997 to 2014. Resuscitation 2016;98:79-84.

47 Chia MY-C, Lu QS, Rahman NH, Doctor NE, Nishiuchi T, Leong BS-H, Tham LP, Goh E-S, Tiah L, Monsomboon A, et al. Characteristics and outcomes of young adults who suffered an out-of-hospital cardiac arrest (OHCA). Resuscitation 2017;111:34-40.

48 Chiang W-C, Chen S-Y, Ko PC-I, Hsieh M-J, Wang H-C, Huang EP-C, Yang C-W, Chong K-M, Chen W-T, Chen S-Y, et al. Prehospital intravenous epinephrine may boost survival of patients with traumatic cardiac arrest: a retrospective cohort study. Scand J Trauma Resusc Emerg Med 2015;23:102.

49 Chien C-Y, Su Y-C, Lin C-C, Kuo C-W, Lin S-C, Weng Y-M. Is 15 minutes an appropriate resuscitation duration before termination of a traumatic cardiac arrest? A case-control study. Am J Emerg Med 2016;34:505-9.

50 David J-S, Gueugniaud P-Y, Riou B, Pham E, Dubien P-Y, Goldstein P, Freysz M, Petit P, Pierre-Yves MD, Riou PhD; Bruno MD, Pham PhD; PhD E. Does the prognosis of cardiac arrest differ in trauma patients? Crit Care Med 2007;35:2251-5.

51 Deasy C, Bray J, Smith K, Harriss L, Morrison C, Bernard S, Cameron P. Traumatic outof-hospital cardiac arrests in Melbourne, Australia. Resuscitation 2012;83:465-70.

52 Djarv T, Axelsson C, Herlitz J, Stromsoe A, Israelsson J, Claesson A. Traumatic cardiac arrest in Sweden 1990-2016 - a population-based national cohort study. Scand J Trauma Resusc Emerg Med 2018;26:30.

53 Duchateau F-X, Hamada S, Raux M, Gay M, Mantz J, Paugam Burtz C, Gauss T, Traumabase Group. Long-Term prognosis after out-of-hospital resuscitation of cardiac arrest in trauma patients: prehospital trauma-associated cardiac arrest. Emerg Med J 2017:34:34-8

54 Falcone RE, Herron H, Johnson R, Childress S, Lacey P, Scheiderer G. Air medical transport for the trauma patient requiring cardiopulmonary resuscitation: a 10-year experience. Air Med J 1995;14:197-204.

55 Fisher B, Worthen M. Cardiac arrest induced by blunt trauma in children. Pediatr Emerg Care 1999;15:274-6

56 Gräsner JT, Wnent J, Seewald S, Meybohm P, Fischer M, Paffrath T, Wafaisade A, Bein B, Lefering R. German resuscitation registry Working group, trauma registry of the German Society for trauma surgery (DGU). cardiopulmonary resuscitation traumatic cardiac arrest-there are survivors. An analysis of two national emergency registries. Crit Care 2011;15:R276.

57 Hillman CM, Rickard A, Rawlins M, Smith JE. Paediatric traumatic cardiac arrest: data from the joint theatre trauma registry. J R Army Med Corps 2016;162:276-9.

58 Huber-Wagner S, Lefering R, Qvick M, Kay MV, Paffrath T, Mutschler W, Kanz KG. Working group on Polytrauma of the German trauma Society (DGU). outcome in 757 severely injured patients with traumatic cardiorespiratory arrest. Resuscitation 2007;75:276-85.

59 Lin Y-R, Syue Y-J, Buddhakosai W, Lu H-E, Chang C-F, Chang C-Y, Chen CH, Chen W-L, Li C-J, HE L, Chang CY, CJ L. Impact of different initial epinephrine treatment time points on the early Postresuscitative hemodynamic status of children with traumatic out-of-hospital cardiac arrest. Medicine 2016:95:e3195.

60 Love KM, Brown JB, Harbrecht BG, Muldoon SB, Miller KR, Benns MV, Smith JW, Baker $\mathrm{CE}$, Franklin GA. Organ donation as an outcome of traumatic cardiopulmonary arrest: a cost evaluation. J Trauma Acute Care Surg 2016;80:792-8.

61 Lundy DJ, Ross SE, Schorr C, Jones AE, Trzeciak S. Outcomes of trauma victims with cardiac arrest who survive to intensive care unit admission. J Trauma 2011:71:E12-16.

62 Molina EJ, Gaughan JP, Kulp H, McClurken JB, Goldberg AJ, Seamon MJ. Outcomes after emergency department thoracotomy for penetrating cardiac injuries: a new perspective. Interact Cardiovasc Thorac Surg 2008;7:845-8.

63 Mollberg NM, Wise SR, Berman K, Chowdhry S, Holevar M, Sullivan R, Vafa A. The consequences of noncompliance with guidelines for withholding or terminating resuscitation in traumatic cardiac arrest patients. J Trauma 2011;71:997-1002.

64 Moore HB, Moore EE, Burlew CC, Biffl WL, Pieracci FM, Barnett CC, Bensard DD, Jurkovich GJ, Fox CJ, Sauaia A. Establishing benchmarks for resuscitation of traumatic 
circulatory arrest: Success-to-Rescue and survival among 1,708 patients. J Am Coll Surg 2016;223:42-50.

65 Murphy JT, Jaiswal K, Sabella J, Vinson L, Megison S, Maxson RT. Prehospital cardiopulmonary resuscitation in the pediatric trauma patient. J Pediatr Surg 2010;45:1413-9.

66 Perron AD, Sing RF, Branas CC, Huynh T. Predicting survival in pediatric trauma patients receiving cardiopulmonary resuscitation in the prehospital setting. Prehosp Emerg Care 2001;5:6-9.

67 Pickens JJ, Copass MK, Bulger EM. Trauma patients receiving CPR: predictors of survival. J Trauma 2005;58:951-8.

68 Powell DW, Moore EE, Cothren CC, Ciesla DJ, Burch JM, Moore JB, Johnson JL. Is emergency department resuscitative thoracotomy futile care for the critically injured patient requiring prehospital cardiopulmonary resuscitation? J Am Coll Surg 2004;199:211-5.
69 Rabinovici R. Sixty-Seven consecutive resuscitative Thoracotomies by a single surgeon. Scand I Surg 2014;103:156-60.

70 Shimazu S, Shatney CH. Outcomes of trauma patients with no vital signs on hospital admission. J Trauma 1983:23:213-6.

71 Stratton SJ, Brickett K, Crammer T. Prehospital pulseless, unconscious penetrating trauma victims: field assessments associated with survival. J Trauma 1998;45:96-100.

72 Vassallo J, Webster M, Barnard EBG, Lyttle MD, PERUKI Smith JE;. Paediatric emergency research in the UK and ireland). epidemiology and aetiology of paediatric traumatic cardiac arrest in England and Wales. Arch Dis Child 2019;104:437-43.

73 Zwingmann J, Lefering R, Bayer J, Reising K, Kuminack K, Südkamp NP, Strohm PC. TraumaRegister DGU( $\left({ }^{\circ}\right)$. Outcome and risk factors in children after traumatic cardiac arrest and successful resuscitation. Resuscitation 2015;96:59-65. 